ARTICLE

\title{
Documentation of preoperative counselling for female sterilisation: a complete audit cycle
}

\author{
Judy Anderson, Eleanor Gunn, Mandy Hunter, Philip Owen
}

\begin{abstract}
Background Female sterilisation is a commonly performed gynaecological procedure that attracts a disproportionate number of complaints and litigation. Documentation of the key counselling issues provides an important record of the information given to the woman prior to undergoing sterilisation
\end{abstract}

Methods Auditable standards were obtained from published guidelines. After the initial audit of 100 cases a proforma was introduced in an effort to improve documentation. A re-audit of 50 cases was undertaken to ascertain compliance of documentation following the introduction of the proforma.

Results The proforma was used in $62 \%$ of cases and in all such cases documentation was $100 \%$ compliant with the auditable standards. Overall, documentation of standards pre- and post-proforma, respectively, was as follows (all the figures quoted are percentage values, with the range given in parentheses): 33 (24-43) vs 68 (53-80) for long-term alternatives, 94 (87-98) vs 78 (62-87) for irreversibility, 96 (90-99) vs 78 (64-88) for failure rate, $48(38-58)$ vs 66 (51-79) for ectopic pregnancy risk if sterilisation fails, 39 (29-49) vs 66 (51-79) for the intended method, 67 (57-76) vs 66 (51-79) for operative risks and 37 (28-47) vs 64 (49-77) for continuing current contraception until sterilisation performed.

Conclusions Documentation of preoperative counselling for female sterilisation is often incomplete and does not comply with published recommendations. The introduction of a proforma resulted in a mixture of both improvement and deterioration of documentation. When the proforma was used, compliance with recommendations was $100 \%$.

J Fam Plann Reprod Health Care 2005; 31(1): 24-25 (Accepted 24 October 2004)

Key message points

- The documentation of preoperative counselling is frequently incomplete.

- A counselling proforma facilitates the collection of adequate documentation.
Department of Gynaecology, Stobhill Hospital, Glasgow, UK Judy Anderson, MB BS, Senior House Officer

Eleanor Gunn, MB BS, Senior House Officer

Mandy Hunter, MB BS, Senior House Officer

Philip Owen, MD, MRCOG, Consultant

Correspondence to: Dr Philip Owen, Department of Gynaecology, Stobhill Hospital, 133 Balornock Road, Glasgow G21 3UW, UK. E-mail: philipowen1@hotmail.com

\section{Introduction}

Female sterilisation is one of the most commonly performed gynaecological procedures and accounts for approximately $10 \%$ of the overall gynaecology caseload. ${ }^{1}$ It is consistently found to be the most common reason for medicolegal claims against gynaecologists and accounts for $19 \%$ of such claims. In an analysis of litigation claims in gynaecology, a high proportion $(46 \%)$ were dismissed as misguided allegations, but $7 \%$ of all the claims were categorised as relating to improper counselling or consent. ${ }^{2}$ Recurring themes included poor communication and lack of adequate documentation in relation to counselling and valid consent preoperatively. ${ }^{2,3} \mathrm{~A}$ Scottish audit group reviewed various aspects of good practice and introduced local criteria in 1996. ${ }^{1}$ Subsequently, when the Royal College of Obstetricians and Gynaecologists (RCOG) reviewed standards of best clinical practice, sterilisation was one of the first clinical guidelines to be published in 1999.4

\section{Aims}

The aims of the study were two-fold as follows. (1) To audit current practice in the documentation of consent issues at the preoperative consultation for female sterilisation against standards recommended by the RCOG. (2) To re-audit the documentation following the introduction of a standardised clinic proforma (Figure 1) incorporating the consent criteria set by the RCOG guideline.

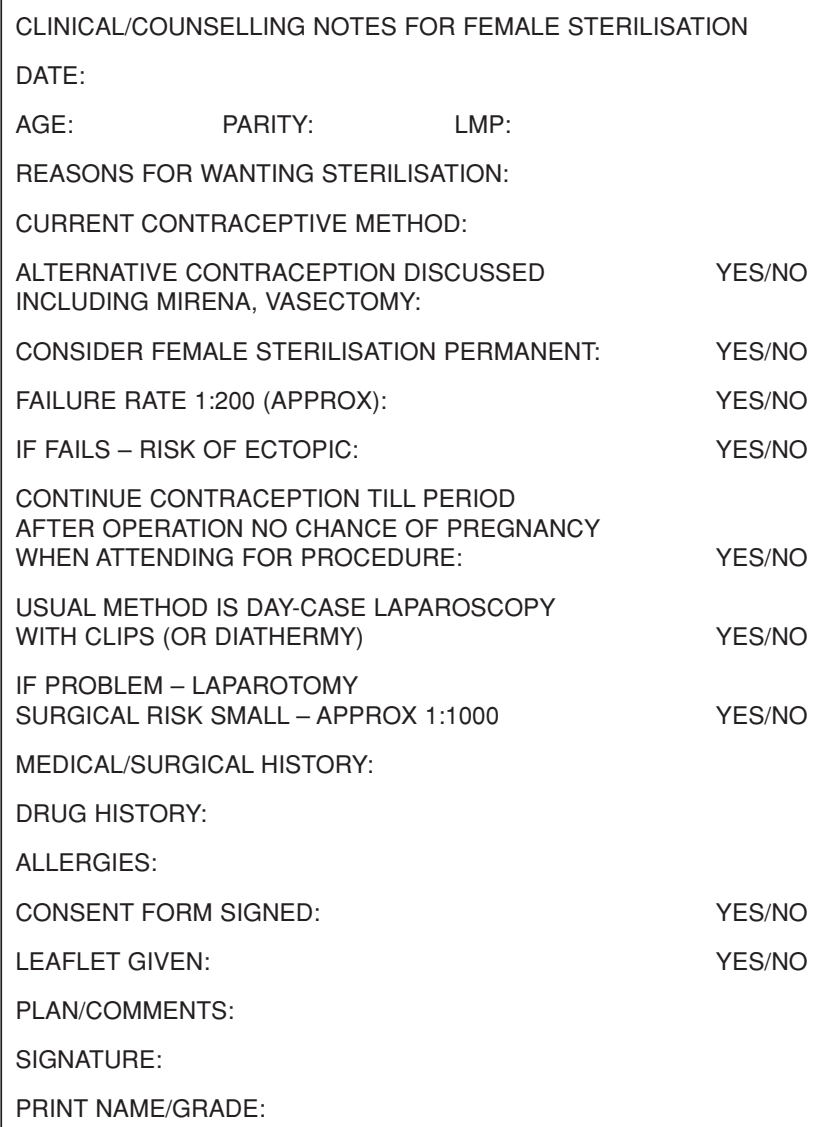

Figure 1 Example of the standardised clinic proforma used in the study 


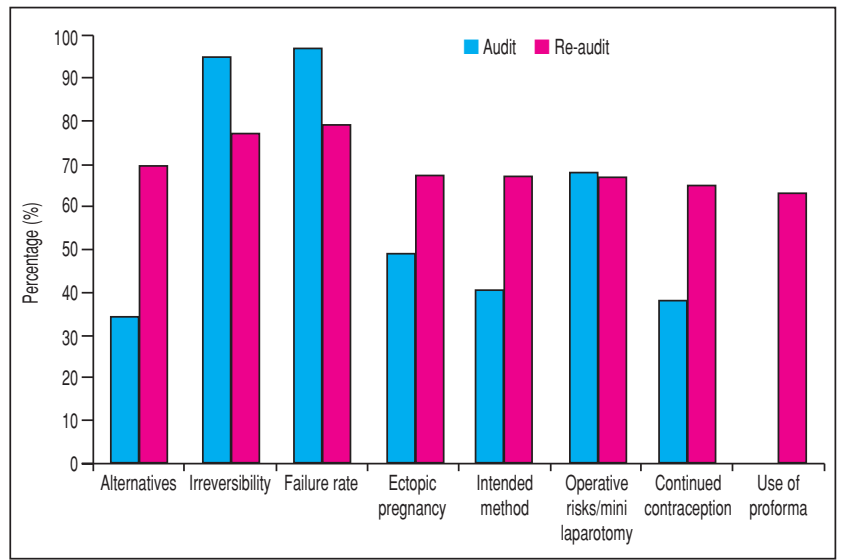

Figure 2 Percentage of patients with documented discussion of each guideline criteria

\section{Methods}

The initial audit involved a retrospective examination of the hospital case notes for 100 women undergoing consecutive laparoscopic sterilisation procedures at Stobhill Hospital from the beginning of January 2000. The re-audit involved a retrospective examination of 50 case notes for women undergoing consecutive sterilisation procedures from the beginning of January 2003. The women were identified from inpatient and day surgery theatre registers. Preoperative counselling was provided by junior and consultant gynaecologists at the time of patient attendance at general gynaecology outpatient clinics.

The audit indicators used are consent criteria set out in the 1999 RCOG Green Top Guideline on 'Male and Female Sterilisation'. 4 It is recommended that several issues be discussed with the patient and documented in the notes at the preoperative visit. These are graded recommendations where (A) is based on randomised trials, (B) on observational or experimental data and (C) on a consensus among experts. The auditable standards we adopted are as detailed below.

- Discussion of alternative long-term methods of contraception, particularly vasectomy and the levonorgestrel intrauterine system (B). (We did not specifically include progesterone implants since Norplant ${ }^{\circledR}$ was not available and Implanon ${ }^{\circledR}$ was not widely available at the time.)

- Irreversibility (B).

- Possibility of failure of sterilisation with quoted lifetime pregnancy risk of 1:200 (B).

- Increased risk of ectopic pregnancy if subsequent conception occurs (B).

- Intended operative method of tubal occlusion (clips, rings or diathermy) (C).

- Operative risks, especially conversion to minilaparotomy $(\mathrm{C})$.

- Continuation of another method of contraception up to the next period after sterilisation has been performed (B).

\section{Results}

The compliance with the guideline is presented in Figure 2. Results include those for the initial audit and re-audit following the availability of a standardised clinic proforma.

\section{Discussion}

Despite the introduction of a standardised proforma, compliance with the standards of practice recommended by the RCOG is less than complete. However, the proforma was only used in $62 \%$ of cases and when it was used documentation was $100 \%$ compliant. The proforma was introduced following consultation with relevant senior gynaecologists in the department and a specific date set for its introduction. A more widely publicised approach within the department aimed at informing all medical and nursing staff may have resulted in its wider adoption.

Following the introduction of the proforma, certain criteria (irreversibility and possible failure) were documented in just over $75 \%$ of case notes compared with over $90 \%$ in the initial audit. A decline in the completeness of documentation during the re-audit was unexpected. Otherwise documentation was more complete, notably concerning alternative methods of contraception, possibility of failure of sterilisation and subsequent pregnancy risk, intended operative method and continuation of another method of contraception. The introduction of the proforma cannot necessarily be held solely responsible for the observed improvements since random variation in the case notes retrieved and/or changes in junior medical staff may also have contributed.

Subsequent to the completion of this audit, the relevant RCOG guideline has been revised and published. 5 The recommendations relating to preoperative counselling have not materially changed, with the exception that written information be provided to support the verbal counselling patients receive.

\section{Conclusions}

Preoperative counselling and its documentation form an important component of obtaining properly informed consent prior to female sterilisation. Despite the introduction of a standardised clinic proforma incorporating the consent criteria set by the RCOG guideline, there remains room for improvement in our practice.

The results of our audit represent practice in a routine clinical setting and are likely to be representative of practice elsewhere in the UK. Despite the mixed results of our re-audit, we would encourage departments to incorporate the use of a preoperative counselling proforma into their practice. A counselling proforma provides objective and easily retrievable evidence of the completeness of preoperative counselling, which forms a firm foundation upon which a claim of substandard counselling can be refuted.

Statements on funding and competing interests

Funding. None identified.

Competing interests. None identified.

References

1 Penney GC, Souter V, Glasier A, Templeton AA. Laparoscopic sterilisation: opinion and practice among gynaecologists in Scotland. Br J Obstet Gynaecol 1997; 104: 71-77.

2 B-Lynch C, Coker A, Dua JA. A clinical analysis of 500 medico-legal claims evaluating the causes and assessing the potential benefit of alternative dispute resolution. Br J Obstet Gynaecol 1996; 103: $1236-1242$.

3 Gupta S, Bewley S. Medicolegal issues in fertility regulation. $\mathrm{Br} J$ Obstet Gynaecol 1998; 105: 818-826.

4 Royal College of Obstetricians and Gynaecologists (RCOG). National Evidence-Based Clinical Guidelines: Male and Female Sterilisation. London, UK: RCOG, 1999. http://www.rcog.org.uk.

5 Royal College of Obstetricians and Gynaecologists (RCOG). National Evidence-Based Clinical Guidelines: Male and Female Sterilisation. London, UK: RCOG, 2004. http://www.rcog.org.uk. 